\author{
JURNAL PERENCANAAN WILAYAH \\ e-ISSN: $2502-4205$ \\ Vol.6., No.2, Oktober 2021 \\ http://ojs.uho.ac.id/index.php/ppw
}

\title{
Tata Kelola Kelembagaan Pedagang Kaki Lima Sekitar Pasar Di Kota Kendari
}

\section{Institutional Governance of Street Vendors Around The Market In Kendari City}

\author{
Habri Jaya ${ }^{1 * *}$, Marsuki Iswandi ${ }^{2)}$, La Ode Alwi ${ }^{3)}$ \\ 1)Program studi Perencanaan Pengembangan Wilayah, Universitas Halu Oleo \\ 2) Fakultas Pertanian, Universitas Halu Oleo \\ 3)Fakultas Pertanian, Universitas Halu Oleo
}

\begin{abstract}
Street vendors in Kendari City tend to increase every year. The consequence of increasing street vendors is the use of sidewalks as a place for buying and selling transactions. The purpose of this study is to determine the characteristics of street vendors and the factors of the presence of street vendors who occupy the sidewalks and shoulders of the road in Kendari City. The method used to analyze the factors of the existence of street vendors who occupy the shoulders and sidewalks and to determine the control system for street vendors who use the shoulders and sidewalks is by using descriptive analysis. The results of this study are the characteristics of street vendors (PKL): main occupation (87\%), types of vegetables into merchandise (14\%), duration of trade $<5$ years (69\%), and area of 2-4 $\mathrm{m} 2(80 \%)$. The factors for the existence of street vendors (PKL) using the road shoulders and sidewalks around the market in Kendari City are weak rule enforcement, transactional systems, no place in the market, and location costs.
\end{abstract}

Keywords : Street Vebdors, Kendari, Manage

\begin{abstract}
ABSTRAK
Jumlah pedangan kaki lima di Kota Kendari cederung mengalami kenaikan disetiap tahunnya. Konsekuensi dari bertambahnya PKL yaitu pemanfaatan trotoar sebagai tempat melakukan transaksi jual beli. Tujuan dari penelitian ini yaitu untuk mengetahui karakteristik pedagang kaki lima dan faktor-faktor keberadaan pedagang kaki lima yang menempati trotoar dan bahu jalan di Kota Kendari. Metode yang digunakan untuk menganalisis faktor-faktor keberadaan pedagang kaki lima yang menempati bahu jalan dan trotoar serta untuk mengetahui sistem penertiban pedagang kaki lima yang menggunakan bahu jalan dan trotoar yaitu dengan menggunakan analisis deskriptif. Hasil dari penelitian ini yaitu karakteristik pedagang kaki lima (PKL): pekerjaan utama (87\%), jenis sayuran menjadi barang dagangan (14\%), lama berdagang $<5$ tahun (69\%), dan luas tempat 2-4 $\mathrm{m}^{2}$ (80\%).Faktor-faktor keberadaan pedagang kaki lima (PKL) menempati bahu jalan dan trotoar disekitar pasar di Kota Kendari adalah lemahnya penegakan aturan, sistem transaksional, tidak ada tempat di dalam pasar, dan biaya lokasi.
\end{abstract}

Kata Kunci: Pedangan Kaki Lima, Kendari, Kelola

\section{PENDAHULUAN}

Pedagang kaki lima mempunyai peranan dalam perkembangan perkotaan, dan merupakan salah satu sektor informal. Sektor ini perlu adanya pembinaan terhadap akvitasnya terutama dalam pengelolaan penempatan lokasi. Pengelolaan penempatan lokasi diantaranya yaitu : a). relokasi (pemugaran), b). stabilisasi (pengaturan), c). removal (pemindahan) (Handoyo, 2013).

Kondisi pedagang kaki lima di Kota Kendari mempunayi tempat tersendiri, dan kondisinya belum sepadat dibandingkan dengan kota-kota di Provinsi lain. Jumlah pedagang kaki lima di Kota Kendari mengalami kenaikan setiap tahunnya, hal ini dapat 
dilihat dengan berkurangnya fungsi trotoar yang merupakan hak bagi pejalan kaki. Trotoar dialih fungsikan sebagai lokasi aktivitas dagang, pertemuan antara pedangan dan pembeli. Hal ini dapat terlihat di sepanjang jalan Bunggasi Kecamatan Poasia, Jalan Lasandara Kecamatan Mandonga dan di Kecamatan Kendari Barat. Pertambahan jumlah pedangan kaki lima mempunyai konseskuensi sendiri yaitu bagaimana cara mengatur dengan baik sehingga tidak menggangu kepentingan orang lain, terlihat estetik, mengurangi kemacetan, terciptanya lingkungan kumuh dan munculnya zona-zona yang tidak teratur.

Kajian tata kelola kelembagaan pedagang kaki lima di Kota Kendari perlu dilakukan dalam menciptakan pemanfaatan ruang yang memiliki keserasian, kenyamanan dan ketertiban baik bagi pedagang kaki lima maupun masyarakat, swasta dan juga bagi pemerintah. Tujuan dari penelitian ini yaitu untuk mengetahui karakteristik pedagang kaki lima dan Faktor-faktor keberadaan pedagang kaki lima yang menempati trotoar dan bahu jalan di Kota Kendari.

\section{METODE PENELITIAN}

\section{Lokasi}

Lokasi penelitian ini terletak di wilayah Kota Kendari yaitu di jalan Pembangunan tempat pelelangan ikan, jalan Lasandara pasar Mandonga, dan jalan Bunggasi pasar Anduonohu.

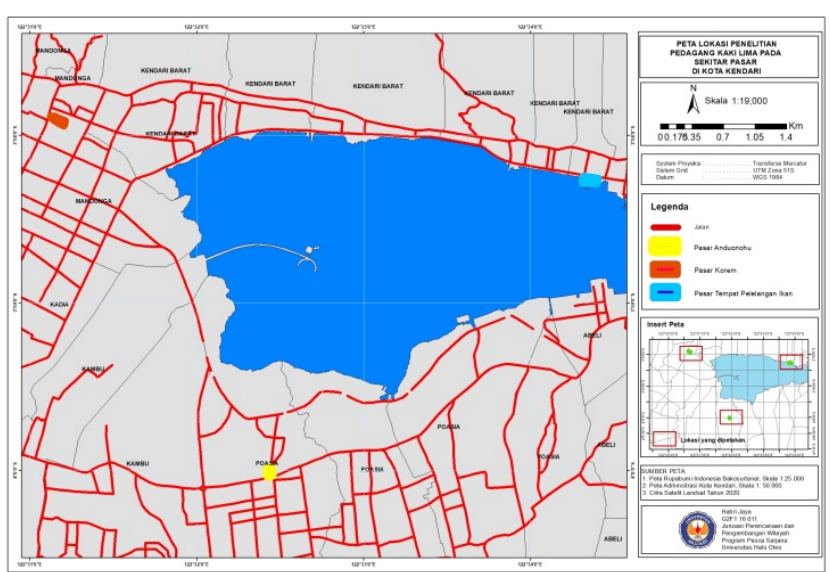

Gambar 1. Peta Lokasi Penelitian

\section{Populasi dan Sampel}

Pada penelitian ini mempunyai populasi yaitu kelompok pedagang kaki lima (PKL) yang berjualan di bahu jalan dan trotoar pada sekitar pasar. Jumlah populasi sebanyak 241 orang. Ridwan dan Engkos, (2011) bahwa teknik pengambilan sampel menggunakan rusmus slovin, dengan rumus:

$n=\frac{N}{N d^{2}+1}$.

Keterangan:

$\mathrm{n}=$ jumlh sampel (orang)

$\mathrm{N}=$ jumlah populasi (orang)

$\mathrm{d} 2=$ presisi $(\%)$

$$
n=\frac{241}{241(0,1)^{2}+1}=71 \text { orang }
$$

Tabel 1. Populasi dan Sampel Menurut Jenis PKL dan Lokasi Pasar, 2020

\begin{tabular}{|c|c|c|c|c|}
\hline No & Pasar & Jenis PKL & Populasi & Jumlah (Orang) \\
\hline \multirow[t]{5}{*}{1} & Anduonohu & a. Gelaran & 59 & 17 \\
\hline & & b. Tenda & 32 & 9 \\
\hline & & c. Tidak Bermotor & 0 & 0 \\
\hline & & d. Bermotor & 10 & 3 \\
\hline & & Jumlah & 101 & 30 \\
\hline \multirow[t]{5}{*}{2} & Mandonga & a. Gelaran & 5 & 1 \\
\hline & & b. Tenda & 22 & 6 \\
\hline & & c. Tidak Bermotor & 9 & 3 \\
\hline & & d. Bermotor & 12 & 4 \\
\hline & & Jumlah & 48 & 14 \\
\hline \multirow[t]{6}{*}{3} & Pelelangan & a. Gelaran & 24 & 7 \\
\hline & & b. Tenda & 48 & 14 \\
\hline & & c. Tidak Bermotor & 5 & 1 \\
\hline & & d. Bermotor & 15 & 4 \\
\hline & & Jumlah & 92 & 27 \\
\hline & & Cotal & 241 & 71 \\
\hline
\end{tabular}

Sumber: Hasil Pengolahan Data 


\section{Variabel Penelitian}

Variabel dalam penelitian ini digunakan sebagai ciri, sifat dan ukuran yang didapatkan dalam satuan penelitian (Sugiyona, 2014). Adapun variabelnya berupa status PKL, jenis dagangan, lama berdagang, luas lokasi, lemahnya penegakkan aturan, sistem transaksional, tidak ada tempat didalam pasar, biaya lokasi, peraturan dan keterkaitan PKL dengan pihak lainnya. Variabel dalam penelitian dapat dilihat pada Tabel 2 dan 3.

Tabel 2. Variabel Penelitian

\begin{tabular}{|c|c|c|c|}
\hline No. & Tujuan & Variabel & Analisis \\
\hline 1. & Karakteristik Pedagang Kaki Lima & $\begin{array}{l}\text { - Status PKL } \\
\text { - Jenis Dagangan } \\
\text { - Lama Berdagang } \\
\text { - Luas Lokasi }\end{array}$ & Deskriptif \\
\hline 2. & $\begin{array}{l}\text { Mengetahui faktor-faktor keberadaan } \\
\text { pedagang kaki lima yang menempati } \\
\text { trotoar dan bahu jalan di Kota Kendari }\end{array}$ & $\begin{array}{l}\text { - Lemahnya penegakan } \\
\text { aturan } \\
\text { - Sistem Transaksional } \\
\text { - Tidak ada Tempat di dalam } \\
\text { Pasar } \\
\text { - Biaya Lokasi }\end{array}$ & Deskriptif \\
\hline 3. & $\begin{array}{l}\text { Sistem penertiban pedagang kaki lima } \\
\text { yang menempati trotoar dan bahu jalan } \\
\text { sekitar pasar di Kota Kendari }\end{array}$ & - Peraturan & Deskriptif \\
\hline 4. & $\begin{array}{l}\text { Pola Kelembagaan pedagang kaki lima } \\
\text { yang menempati trotoar dan bahu jalan } \\
\text { sekitar pasar di Kota Kendari }\end{array}$ & $\begin{array}{l}\text { - Keterkaitan PKL dengan } \\
\text { pihak lain }\end{array}$ & Deskriptif \\
\hline
\end{tabular}

Sumber: Hasil Pengolahan Data

Table 3. Aspek Yang Diteliti, Variabel, Sumber Dan Teknik Pengumpulan Data.

\begin{tabular}{|c|c|c|c|c|}
\hline No. & Aspek & Variabel & Sumber Data & $\begin{array}{c}\text { Teknik } \\
\text { Pengumpulan data }\end{array}$ \\
\hline 1. & keberadaan PKL & $\begin{array}{l}\text { Faktor-faktor dalam } \\
\text { menempati bahu } \\
\text { jalan dan trotoar }\end{array}$ & Pengelola pasar & $\begin{array}{l}\text { Studi pustaka, } \\
\text { wawancara }\end{array}$ \\
\hline 2. & $\begin{array}{l}\text { Pemanfaatan ruang - } \\
\text { berjualan }\end{array}$ & penertiban & - Satpol PP & $\begin{array}{l}\text { - Wawancara } \\
\text { - Studi pustaka }\end{array}$ \\
\hline
\end{tabular}

Sumber: Hasil Pengolahan Data

\section{Teknik Analisis Data}

\section{Analisis Deskriptif}

Analisis ini digunakan untuk mendeskripsikan, menggambarkan kejadian penggunaan ruang pedagang kaki lima dalam berjualan di tepi atau di sekitar pasar yang telah menimbulkan dampak negatif seperti kesemrawutan, kemacetan. Penelitian ini yaitu penelitian kualitatif Menurut (Creswell, 2010), dengan metode wawancara terbuka dengan pendekatan naratif. 


\section{HASIL DAN PEMBAHASAN}

\section{Sarana dan Prasarana Perdagangan}

Menurut Kottler (2002) pasar adalah suatu tempat fisik dimana pembeli dan penjual berkumpul untuk mempertukarkan barang dan jasa. Pasar sebagai sebuah kelembagaan yang dikelola oleh salah satu institusi pasar yang di tunjuk oleh pemerintah pusat/daerah untuk menjalankan fungsi pengawasan, penertiban aset pasar, pengumpulan pendapatan yang sah yang sesuai perda yang dilaksanakan untuk kepentingan bersama (Yustika, 2006).

Perkembangan wilayah perkotaan yang dibarengi dengan meningkatnya jumlah penduduk diwilayah perkotaan. Pemerintah Kota Kendari terus mengembangkan dan memperbanyak fasilitas perdagangan guna menggerakkan perekonomian masyarakat. Salah satu wujud kepedulian pemkot adalah dengan membangun pasar tradisional. Semua. pasar tradisional yang sudah ada diperbaiki fasilitasnya, dibangun dengan konsep yang lebih modern dan representatif

Beberapa pasar tradisional yang dikembangkan selama ini mencapai 8 buah Pasar tradisional tersebut meliputi : pasar sentral Kendari, pasar baru Wua-Wua, pasar Baruga, pasar Anduonohu, pasar Lapulu, pasar Purirano dan pasar Nambo. Selain itu ditunjang oleh berbagai fasilitas perekonomian lain seperti bank pemerintah, bank swasta, perusahaan, toko, kios dan warung. Jumlah toko, kios dan warung di Kota Kendari dapat dilihat pada table 4 .

Tabel 4. Jumlah Pasar Tradisional di Kota Kendari

\begin{tabular}{lccccc}
\hline \multicolumn{1}{c}{ Uraian } & 2016 & 2017 & 2018 & 2019 & 2020 \\
\hline $\begin{array}{l}\text { Pasar } \\
\text { tradisional }\end{array}$ & 8 & 8 & 8 & 10 & 10 \\
\hline
\end{tabular}

Sumber: Hasil Pengolahan Data

Tenaga Kerja
Kondisi ketenagakerjaan di Kota Kendari di tandai oleh jumlah pengangguran sebanyak 11.224 orang, dengan pencari kerja yang terdaftar sebanyak 22.167 orang. Jumlah ini masih sangat kecil jika di bandingkan dengan jumlah pengangguran pada tahun 2018 sebesar 12. 025 orang. Pemerintah Kota Kendari terus berbenah membuka lapangan usaha berupa UMKM seperti pengembangan industri kerajinan mebel, pangan tradisional yang dibina dan di awasi oleh dinas terkait melalui badan layanan usaha daerah. Dibawah ini disajikan tabel jumlah pengangguran berdasarkan jenis kelamin.

Tabel 5. Jumlah Pengangguran Berdasarkan Jenis Kelamin

\begin{tabular}{llccc}
\hline No. & Kecamatan & $\begin{array}{r}\text { Laki- } \\
\text { Laki }\end{array}$ & Wanita & Jumlah \\
\hline 1. & Nambo & 344 & 676 & 1,020 \\
2. & Abeli & 604 & 552 & 1,156 \\
3. & Poasia & 760 & 287 & 1,047 \\
4. & Kambu & 440 & 657 & 1,097 \\
5. & Puuwatu & 285 & 810 & 1.095 \\
6. & Kadia & 671 & 186 & 857 \\
7. & Wua-Wua & 206 & 316 & 522 \\
8. & Mandonga & 782 & 1,019 & 1,801 \\
9. & Baruga & 673 & 486 & 1,159 \\
10. & Kendari & 530 & 220 & 750 \\
11. & Kendari Barat & 289 & 431 & 720 \\
\hline & Jumlah & 5,584 & 5,640 & 11,224 \\
\hline
\end{tabular}

Sumber: Renstra Dinas Tenaga Kerja Kota Kendari, 2018-2022

\section{Karakteristik Pedagang Kaki Lima}

\section{a. Status Pekerjaan}

Pekerjaan pada umumnya terdiri atas pekerjaan utama dan pekerjaan sampingan. Kedua pekerjaan itu dibedakan oleh alokasi waktu yang digunakan. Jika alokasi waktunya lebih banyak maka dapat dinyatakan sebagai pekerjaan utama sedangkan alokasi waktu yang sedikit sebagai pekerjaan sampingan.

Tabel 6. Status Pekerjaan Pedagang Kaki Lima, 2020

\begin{tabular}{|c|c|c|c|c|c|c|c|c|c|c|c|c|}
\hline \multirow[b]{2}{*}{ No. } & \multirow[b]{2}{*}{$\begin{array}{c}\text { Status } \\
\text { Pekerjaan }\end{array}$} & \multicolumn{3}{|c|}{ Pasar Anduonohu } & \multicolumn{3}{|c|}{ Pasar Mandonga } & \multicolumn{3}{|c|}{ Tempat Pelelangan } & \multicolumn{2}{|c|}{ Total } \\
\hline & & Orang & $\begin{array}{c}\text { Lokasi } \\
\text { (\%) }\end{array}$ & $\begin{array}{c}\text { Total } \\
(\%)\end{array}$ & Orang & $\begin{array}{c}\text { Lokasi } \\
\text { (\%) }\end{array}$ & $\begin{array}{l}\text { Total } \\
(\%)\end{array}$ & Orang & $\begin{array}{c}\text { Lokasi } \\
(\%)\end{array}$ & $\begin{array}{l}\text { Total } \\
\text { (\%) }\end{array}$ & Orang & $\%$ \\
\hline & Jtama & 24 & 80 & 39 & 14 & 100 & 23 & 24 & 89 & 39 & 62 & 87 \\
\hline & Sampingan & 6 & 20 & 67 & 0 & 0 & 0 & 3 & 11 & 33 & 9 & 13 \\
\hline & Jumlah & 30 & 100 & & 14 & 100 & & 27 & 100 & & 71 & 100 \\
\hline
\end{tabular}

Sumber: Hasil Pengolahan Data 
Tabel 6 menunjukan Pedagang kaki lima merupakan pekerjaan utama yang dilakukan oleh 62 orang atau 87 persen. Status tersebut paling banyak dilakukan oleh pedagang di pasar anduonohu dan tempat pelelangan masing-masing 24 orang atau 39 persen. Adapun yang menjadikan sebagai pekerjaan sampingan sebanyak 9 orang atau 13 persen, banyak terdapat di Pasar Anduonohu yakni 6 orang atau 20 persen. Pekerjaan sampingan dilakukan untuk menambah penghasilan agar dapat memenuhi kebutuhan sehari-hari dan kebutuhan lainnya.

\section{b. Jenis Barang Dagangan}

Barang dagangan menjadi dasar pedagang kaki lima untuk berdagang. Jika tidak memiliki barang dagangan maka mereka tidak akan ke pasar. Oleh karena itu mempunyai peranan penting agar dapat melaksanakan aktifitas rutin sebagai pedagang kaki lima. Barang dagangan tersebut beragam antar pedagang satu dengan lainnya. Jenis Barang Dagangan Pedagang Kaki Lima dapat dilihat pada Tabel 7.

Tabel 7. Jenis Barang Dagangan Pedagang Kaki Lima, 2020

\begin{tabular}{|c|c|c|c|c|c|c|c|c|c|c|c|c|}
\hline \multirow[b]{2}{*}{ No. } & \multirow[b]{2}{*}{ Jenis Dagangan } & \multicolumn{3}{|c|}{ Pasar Anduonohu } & \multicolumn{3}{|c|}{ Pasar Mandonga } & \multicolumn{3}{|c|}{ Tempat Pelelangan } & \multicolumn{2}{|c|}{ Total } \\
\hline & & Orang & $\begin{array}{c}\text { Lokasi } \\
\text { (\%) }\end{array}$ & $\begin{array}{c}\text { Total } \\
\text { (\%) }\end{array}$ & Orang & $\begin{array}{c}\text { Lokasi } \\
\text { (\%) }\end{array}$ & $\begin{array}{c}\text { Total } \\
\text { (\%) }\end{array}$ & Orang & $\begin{array}{c}\text { Lokasi } \\
\text { (\%) }\end{array}$ & $\begin{array}{c}\text { Total } \\
(\%)\end{array}$ & Orang & $\%$ \\
\hline 1. & Sayuran & 10 & 33 & 100 & 0 & 0 & 0 & 0 & 0 & 0 & 10 & 14 \\
\hline 2. & Buah-Buahan & 3 & 10 & 50 & 1 & 7 & 17 & 2 & 7 & 33 & 6 & 8 \\
\hline 3. & Aksesoris & 1 & 3 & 11 & 6 & 43 & 67 & 2 & 7 & 22 & 9 & 13 \\
\hline & Minyak Goreng dan Telur & 2 & 7 & 50 & 0 & 0 & 0 & 2 & 7 & 50 & 4 & 6 \\
\hline & $\begin{array}{l}\text { Jeruk Nipis, Tahu dan } \\
\text { Tempe }\end{array}$ & 2 & 7 & 67 & 0 & 0 & 0 & 1 & 4 & 33 & 3 & 4 \\
\hline & Makanan & 0 & 0 & 0 & 4 & 29 & 40 & 6 & 22 & 60 & 10 & 14 \\
\hline & Sayuran, Cabe \& Tomat & 5 & 17 & 71 & 0 & 0 & 0 & 2 & 7 & 29 & 7 & 10 \\
\hline & Sayuran, Tahu, dan Tempe & 1 & 3 & 100 & 0 & 0 & 0 & 0 & 0 & 0 & 1 & 1 \\
\hline & Bawang, Cabe \& Tomat & 4 & 13 & 67 & 0 & 0 & 0 & 2 & 7 & 33 & 6 & 8 \\
\hline 10. & Bawang dan Jeruk & 2 & 7 & 100 & 0 & 0 & 0 & 0 & 0 & 0 & 2 & 3 \\
\hline 11. & Umbi-umbian & 0 & 0 & 0 & 1 & 7 & 50 & 1 & 4 & 50 & 2 & 3 \\
\hline 12. & Sepatu \& Sandal & 0 & 0 & 0 & 1 & 7 & 33 & 2 & 7 & 67 & 3 & 4 \\
\hline 13. & Penjahit Sepatu & 0 & 0 & 0 & 1 & 7 & 100 & 0 & 0 & 0 & 1 & 1 \\
\hline 14. & Pakaian & 0 & 0 & 0 & 0 & 0 & 0 & 1 & 4 & 100 & 1 & 1 \\
\hline 15. & Bunga & 0 & 0 & 0 & 0 & 0 & 0 & 1 & 4 & 100 & 1 & 1 \\
\hline 16. & Kue & 0 & 0 & 0 & 0 & 0 & 0 & 2 & 7 & 100 & 2 & 3 \\
\hline 17. & Ayam & 0 & 0 & 0 & 0 & 0 & 0 & 1 & 4 & 100 & 1 & 1 \\
\hline 18. & Parang dan Cobek & 0 & 0 & 0 & 0 & 0 & 0 & 2 & 7 & 100 & 2 & 3 \\
\hline & Jumlah & 30 & 100 & & 14 & 100 & & 27 & 100 & & 71 & 100 \\
\hline
\end{tabular}

Sumber: Hasil Pengolahan Data

Sayuran dan makanan menjadi jenis barang yang banyak di jual oleh pedagang kaki lima masingmasing 10 orang atau 14 persen. Pedagang yang hanya menjual sayuran hanya terdapat di Pasar Anduonohu yakni 10 orang atau 100\%. Namun terdapat pula pedagang yang menjual sayuran, cabe dan tomat sebanyak 7 orang atau 10 persen yang banyak terdapat di Pasar Anduonohu yakni 5 orang atau 71 persen. Selain untuk kebutuhan pangan terdapat pula untuk kebutuhan sandang berupa pakaian yang hanya terdapat di tempat pelelangan. Jika ingin membeli parang dan cobek tersedia di tempat pelelangan yang dijual oleh 2 orang.

\section{c. Lama Berdagang}

Lama berdagang merupakan interval waktu dari pertama kali menjadi pedagang kaki lima dengan berlangsungnya kegiatan penelitian. Semakin lama berdagang maka semakin berpengalaman dalam menentukan jenis barang dagangan yang akan di jual. Jika kurang dari 5 tahun maka kurang berpengalaman, antara $5-10$ tahun cukup berpengalaman, dan lebih dari 10 tahun sangat berpengalaman. Tabel 8 menunjukan bahwa lama pedagang kaki lima sebagian besar kurang sari 5 tahun yakni 49 orang atau 69 persen yang terbanyak di Pasar Anduonohu dan tempat pelelangan masingmasing sejumlah 20 orang atau 41 persen. Adapun sangat berpengalaman 9 lebih dari 10 tahun) hanya 2 
orang atau 3 persen masing-masing 1 orang atau 3 pelelangan.

persen terdapat di Pasar Anduonohu dan tempat

Tabel 8. Lama Berdagang Pedagang Kaki Lima, 2020

\begin{tabular}{|c|c|c|c|c|c|c|c|c|c|c|c|c|}
\hline \multirow[b]{2}{*}{ No. } & \multirow{2}{*}{$\begin{array}{c}\text { Lama } \\
\text { Berdagang } \\
\text { (Tahun) }\end{array}$} & \multicolumn{3}{|c|}{ Pasar Anduonohu } & \multicolumn{3}{|c|}{ Pasar Mandonga } & \multicolumn{3}{|c|}{ Tempat Pelelangan } & \multicolumn{2}{|c|}{ Total } \\
\hline & & Orang & $\begin{array}{c}\text { Lokasi } \\
\text { (\%) }\end{array}$ & $\begin{array}{c}\text { Total } \\
\text { (\%) }\end{array}$ & Orang & $\begin{array}{c}\text { Lokasi } \\
(\%)\end{array}$ & $\begin{array}{c}\text { Total } \\
(\%)\end{array}$ & Orang & $\begin{array}{c}\text { Lokasi } \\
\text { (\%) }\end{array}$ & $\begin{array}{c}\text { Total } \\
(\%)\end{array}$ & Orang & $\%$ \\
\hline 1. & $<5$ & 20 & 67 & 41 & 9 & 64 & 18 & 20 & 74 & 41 & 49 & 69 \\
\hline 2. & $5-10$ & 9 & 30 & 45 & 5 & 36 & 25 & 6 & 22 & 30 & 20 & 28 \\
\hline 3. & $>10$ & 1 & 3 & 50 & 0 & 0 & 0 & 1 & 4 & 50 & 2 & 3 \\
\hline & Jumlah & 30 & 100 & & 14 & 100 & & 27 & 100 & & 71 & 100 \\
\hline
\end{tabular}

Sumber: Hasil Pengolahan Data

\section{d. Luas Tempat}

Luas tempat pedagang kaki lima dipengaruhi oleh banyaknya barang dagangan yang akan dijual. Tabel 9 menunjukan bahwa paling banyak menggunakan tempat seluas $2-4 \mathrm{~m} 2$ yakni 57 orang atau 80 persen. Pada luasan tersebut paling banyak di Pasar Anduonohu sebanyak 27 orang atau 47 persen dan 21 orang atau 37 persen di tempat pelelangan.
Selain itu yang menggunakan luas tempat 8 $10 \mathrm{~m}^{2}$ hanya terdapat di Pasar Anduonohu sebanyak 3 orang atau 100 persen. Pedagang kaki lima yang menggunakan luasan tersebut merupakan pedagang buah-buahan yang menggunakan mobil open. Hal ini dapat mengganggu pengguna jalan karena jalan menjadi sempit untuk dilalui.

Tabel 9. Luas Tempat Pedagang Kaki Lima, 2020

\begin{tabular}{ccccccccccccc}
\hline & \multirow{2}{*}{$\begin{array}{c}\text { Luas Tempat } \\
\text { Berdagang }\left(\mathrm{m}^{2}\right)\end{array}$} & \multicolumn{3}{c}{ Pasar Anduonohu } & \multicolumn{3}{c}{ Pasar Mandonga } & \multicolumn{3}{c}{ Tempat Pelelangan } & \multicolumn{2}{c}{ Total } \\
\cline { 3 - 12 } & & $\begin{array}{c}\text { Orasi } \\
(\%)\end{array}$ & $\begin{array}{c}\text { Total } \\
(\%)\end{array}$ & Orang & $\begin{array}{c}\text { Lokasi } \\
(\%)\end{array}$ & $\begin{array}{c}\text { Total } \\
(\%)\end{array}$ & $\begin{array}{c}\text { Orang } \\
\text { Lokasi } \\
(\%)\end{array}$ & $\begin{array}{c}\text { Total } \\
(\%)\end{array}$ & Orang & $\%$ \\
\hline 1. & $2-4$ & 27 & 90 & 47 & 9 & 64 & 16 & 21 & 78 & 37 & 57 & 80 \\
2. & $5-7$ & 0 & 0 & 0 & 5 & 36 & 45 & 6 & 22 & 55 & 11 & 15 \\
3. & $8-10$ & 3 & 10 & 100 & 0 & 0 & 0 & 0 & 0 & 0 & 3 & 4 \\
\hline & Jumlah & 30 & 100 & & 14 & 100 & & 27 & 100 & 71 & 100 \\
\hline
\end{tabular}

Sumber: Hasil Pengolahan Data

\section{Faktor - faktor Keberadaan Pedagang Kaki Lima yang menempati Bahu Jalan dan Trotoar}

Pedagang kaki lima sebagai salah satu sektor alternatif yang dapat dimasuki semua kalangan masyarakat, sektor informal mempunyai kekhususan atau ciri khas meliputi a). sektor informal mudah di akses, b) tidak memerlukan ijin untuk beroperasi, c) tidak memerlukan keahlian tetentu, d) modal untuk memulai usaha sangat minim/tidak membutuhkan modal besar.

Selain itu ada banyak faktor yang membuat pedagang kaki lima untuk bertahan pada satu wilayah sedangkan daerah tersebut merupakan wilayah yang tidak diperuntukkan aktivitas berdagang, contohnya adalah area sekitar pasar. Faktor penyebab sehingga pedagang kaki lima (PKL) menempati ruang disekitar pasar dapat dilihat dari beberapa aspek seperti kesulitan ekonomi, lapangan pekerjaan yang tidak tersedia, keterbatasan keterampilan/keahlian, dan tingkat pendidikan. (Maulidiyah, 2016).

\section{- Lemahnya Penegakan Aturan}

Pedagang kaki lima yang berjualan di bahu jalan dan bahkan telah menempati aspal tanpa ada izin dari PD Pasar/pemerintah. Hal ini ditandai dengan tanggapan pedagang kaki lima bahwa mereka tidak mendapat izin dari PD pasar/pemerintah sebagaimana ditampilkan pada Tabel 10. Lokasi yang ditempati PKL telah dilakukan penertiban agar tidak menjual pada trotoar dan bahu jalan. Hal ini sesuai tanggapan PKL bahwa 71 orang atau 100 persen menyatakan Satuan Polisi Pamong Praja (Satpol PP) melakukan penertiban dagangan PKL. Lokasi yang telah di tempati pedagang kaki lima yang telah dilakukan penertiban dapat dilhat pada Tabel 11. 
Tabel 10. Izin berdagang dari PD Pasar/Pemerintah Pedagang Kaki Lima, 2020

\begin{tabular}{cccccccc}
\hline \multirow{2}{*}{$\begin{array}{c}\text { Izin Berdagang dari PD } \\
\text { Pasar/ Pemerintah }\end{array}$} & \multicolumn{2}{c}{ Pasar Anduonohu } & \multicolumn{2}{c}{ Pasar Mandonga } & \multicolumn{2}{c}{ Pelelangan } & Total \\
\cline { 2 - 8 } & Orang & Total (\%) & Orang & $\begin{array}{c}\text { Total } \\
(\%)\end{array}$ & Orang & Total (\%) & Orang \\
\hline Tidak & 30 & 42 & 14 & 20 & 27 & 38 & 71 \\
\hline
\end{tabular}

Sumber: Hasil Pengolahan Data

Tabel 11. Penertiban Pedagang Kaki Lima oleh Pihak Satuan Polisi Pamong Praja, 2020

\begin{tabular}{cccccccc}
\hline \multirow{2}{*}{$\begin{array}{c}\text { Penertiban Pihak Satpol } \\
\text { PP/Pemerintah }\end{array}$} & \multicolumn{2}{c}{ Pasar Anduonohu } & \multicolumn{2}{c}{ Pasar Mandonga } & \multicolumn{2}{c}{ Pelelangan } & Total \\
\cline { 2 - 9 } & Orang & $\begin{array}{c}\text { Total } \\
(\%)\end{array}$ & Orang & $\begin{array}{c}\text { Total } \\
(\%)\end{array}$ & Orang & $\begin{array}{c}\text { Total } \\
(\%)\end{array}$ & Orang \\
\hline Ya & 30 & 42 & 14 & 20 & 27 & 38 & 71 \\
\hline
\end{tabular}

Sumber: Hasil Pengolahan Data

Penertiban PKL dilakukan oleh Satpol PP beragam karena terdapat 1 dan 2 kali dalam sehari.Pada Pasar Anduonohu penertiban dilakukan sebanyak 1 kali sehari. Begitu pula di tempat pelelangan hanya 1 kali dalam sehari sedangkan pasar mandonga dilakukan 2 kali sehari. Hal ini menunjukan perbedaan perlakuan dalam penertiban sehingga PKL masih tetap berjualan di bahu jalan dan trotoar seperti yang ditampilkan pada Tabel 12.

Tabel 12. Frekuensi Penertiban PKL oleh Pihak Satuan Polisi Pamong Praja dalam Sehari, 2020

\begin{tabular}{|c|c|c|c|c|c|c|c|c|c|c|c|c|}
\hline \multirow[b]{2}{*}{ No. } & \multirow{2}{*}{$\begin{array}{c}\text { Frekuensi } \\
\text { Penertiban } \\
\text { dalam Sehari } \\
\text { (Kali) }\end{array}$} & \multicolumn{3}{|c|}{ Pasar Anduonohu } & \multicolumn{3}{|c|}{ Pasar Mandonga } & \multicolumn{3}{|c|}{ Pelelangan } & \multicolumn{2}{|c|}{ Total } \\
\hline & & Orang & $\begin{array}{c}\text { Lokasi } \\
\text { (\%) }\end{array}$ & $\begin{array}{c}\text { Total } \\
(\%)\end{array}$ & Orang & $\begin{array}{c}\text { Lokasi } \\
\text { (\%) }\end{array}$ & $\begin{array}{c}\text { Total } \\
(\%)\end{array}$ & Orang & $\begin{array}{c}\text { Lokasi } \\
(\%)\end{array}$ & $\begin{array}{c}\text { Total } \\
(\%)\end{array}$ & Orang & $\%$ \\
\hline 1 & 1 & 30 & 10 & 53 & 0 & 0 & 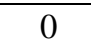 & 2 & 100 & 4 & 57 & 80 \\
\hline 2. & 2 & 0 & 0 & 0 & 14 & 100 & 100 & 0 & 0 & 0 & 14 & 20 \\
\hline & Jumlah & 30 & 100 & & 14 & 100 & & 27 & 100 & & 71 & 100 \\
\hline
\end{tabular}

Sumber: Hasil Pengolahan Data

\section{- Sistem Transaksional}

Transaksional merupakan adanya tujuan-tujuan tertentu dalam menentukan lokasi PKL. Tabel 13 menunjukkan bahwa 71 orang atau 100 persen menyatakan yang menentukan lokasi PKL adalah preman. Hal ini yang mnyebabkan PKL semakin berkembang dengan adanya tindakan preman yang bukan menjadi wewenangnya.

Tabel 13. Penentuan Lokasi Pedagang Kaki Lima, 2020

\begin{tabular}{cccccccc}
\hline \multirow{2}{*}{$\begin{array}{c}\text { Penentu } \\
\text { Lokasi }\end{array}$} & \multicolumn{2}{c}{ Pasar Anduonohu } & \multicolumn{2}{c}{ Pasar Mandonga } & \multicolumn{2}{c}{ Pelelangan } & Total \\
\cline { 2 - 8 } & Orang & Total $(\%)$ & Orang & Total $(\%)$ & Orang & Total (\%) & Orang \\
\hline Preman & 30 & 42 & 14 & 20 & 27 & 38 & 71 \\
\hline
\end{tabular}

Sumber: Hasil Pengolahan Data

Pedagang kaki lima membayar tagihan bulanan dan harian kepada preman bukan pada PD Pasar. Hal tersebut sesuai dengan tanggapan PKL sebanyak 71 orang atau 100 persen mereka membayar kepada tagihan bulanan dan harian kepada preman.

Pola pikir heuristik PKL terhadap berbagai problematika sosial memperkukuh atribut pelindung terhadap preman. PKL memperhatikan bagaimana aturan main (yang telah ditetapkan secara terselubung oleh pihak dominan melalui pemberian upeti terhadap aparat secara terselubung) dapat menjamin eksistensi perdagangan mereka di pasar. Preman sebagai pelaku pemungutan liar dapat dikatakan hanyalah pelaku yang menjalankan aturan main 
untuk menjamin eksistensi pedagang kaki lima (Tabel 14). Dinamika oposisi internal yang berlaku dalam struktur memperhatikan aturan main yang berkaitan dengan tingkat kontrol atas modal sehubungan dengan interaksi preman, PKL dan aparat. Interaksi kemudian membentuk simbiosis yang bersifat tarik menarik kepentingan dan saling memanfaatkan antara berbagai pihak untuk menguasai modal-modal yang tersebar dalam habitus kekuasaan (Ardi, 2005)

Tabel 14. Membayar Tagihan Bulanan dan Harian, 2020

\begin{tabular}{cccccccc}
\hline $\begin{array}{c}\text { Membayar Tagihan } \\
\text { Bulanan dan Harian }\end{array}$ & Orang & $\begin{array}{c}\text { Total } \\
(\%)\end{array}$ & Orang & Total $(\%)$ & Orang & $\begin{array}{c}\text { Total } \\
(\%)\end{array}$ & Orang \\
\hline Preman & 30 & 42 & 14 & 20 & 27 & 38 & 71 \\
\hline
\end{tabular}

Sumber: Hasil Pengolahan Data

- Tidak Ada Tempat di Dalam Pasar

Pedagang kaki lima yang menjual di bahu jalan dan trotoar mengemukakan beragam alasan tidak menjual didalam pasar. Alasan tersebut diantaranya penuh, tinggi tagihan dan sulit mendapatkan pembeli. Tabel 15 menunjukan bahwa sebanyak 25 orang atau 35 persen $\mathrm{PKL}$ tidak menjual di dalam pasar karena penuh. Alasan tersebut banyak dikemukakan oleh pedagang Pasar Anduonohu yakni sebanyak 15 orang atau 60 persen dan paling sedikit di pasar mandonga sebanyak 2 orang atau 8 persen. Namun terdapat pula yang beralasan penuh dan tinggi tagihan yakni sebanyak 25 orang atau 35 persen. Alasan tersebut sebanyak 12 orang atau 48 persen dikemukakan PKL pasar mandonga. Alasan yang paling sedikit dikemukakan 1 orang yang menjual pada tempat pelelangan adalah penuh, tagihan tinggi dan sulit mendapatkan pembeli. Pelanggaran yang dilakukan PKL yakni menjual pada bahu jalan dan trotoar sehingga mengganggu pejalan kaki dan kendaraan yang lewat. Tabel 16 menunjukan bahwa sebanyak 40 orang atau 56 persen PKL menjual diatas aspal yang terdapat di Pasar Anduonohu sebnayak 14 orang atau 47 persen. Selain itu terdapat pula PKL yang menjual dengan jarak $26-50 \mathrm{~cm}$ dari jalan raya sebanyak 7 orang atau 100 persen.

Tabel 15. Alasan Pedagang Kaki Lima Tidak Berdagang di dalam Pasar, 2020

\begin{tabular}{|c|c|c|c|c|c|c|c|c|c|c|c|c|}
\hline \multirow[b]{2}{*}{ No. } & \multirow[b]{2}{*}{$\begin{array}{c}\text { Alasan Tidak Bedagang } \\
\text { di Dalam Pasar }\end{array}$} & \multicolumn{3}{|c|}{ Pasar Anduonohu } & \multicolumn{3}{|c|}{ Pasar Mandonga } & \multicolumn{3}{|c|}{ Tempat Pelelangan } & \multicolumn{2}{|c|}{ Total } \\
\hline & & Orang & $\begin{array}{l}\text { Lokasi } \\
(\%)\end{array}$ & $\begin{array}{l}\text { Total } \\
(\%)\end{array}$ & Orang & $\begin{array}{l}\text { Lokasi } \\
(\%)\end{array}$ & $\begin{array}{c}\text { Total } \\
(\%)\end{array}$ & Orang & $\begin{array}{c}\text { Lokasi } \\
(\%)\end{array}$ & $\begin{array}{c}\text { Total } \\
(\%)\end{array}$ & Orang & $\%$ \\
\hline 1. & Penuh & 15 & 50 & 60 & 2 & 14 & 8 & 8 & 30 & 32 & 25 & 35 \\
\hline 2. & Tinggi Tagihan & 0 & 0 & 0 & 0 & 0 & 0 & 4 & 15 & 16 & 4 & 6 \\
\hline 3. & $\begin{array}{l}\text { Sulit Mendapatkan } \\
\text { Pembeli }\end{array}$ & 4 & 13 & 80 & 0 & 0 & 0 & 1 & 4 & 4 & 5 & 7 \\
\hline 4. & $\begin{array}{l}\text { Penuh dan Tinggi } \\
\text { Tagihan }\end{array}$ & 7 & 23 & 28 & 12 & 86 & 48 & 6 & 22 & 24 & 25 & 35 \\
\hline 5. & $\begin{array}{l}\text { Penuh dan Sulit } \\
\text { Mendapatkan Pembeli }\end{array}$ & 1 & 3 & 20 & 0 & 0 & 0 & 4 & 15 & 16 & 5 & 7 \\
\hline 6. & $\begin{array}{l}\text { Tinggi Tagihan dan Sulit } \\
\text { Mendapatkan Pembeli }\end{array}$ & 3 & 10 & 50 & 0 & 0 & 0 & 3 & 11 & 12 & 6 & 8 \\
\hline 7. & $\begin{array}{l}\text { Penuh, Tinggi Tagihan } \\
\text { dan Sulit Mendapatkan } \\
\text { Pembeli }\end{array}$ & 0 & 0 & 0 & 0 & 0 & 0 & 1 & 4 & 4 & 1 & 1 \\
\hline & Jumlah & 30 & 100 & & 14 & 100 & & 27 & 100 & & 71 & 100 \\
\hline
\end{tabular}

Sumber: Hasil Pengolahan Data 
Tabel 16. Jarak Tempat Pedagang Kaki Lima dengan Aspal, 2020

\begin{tabular}{|c|c|c|c|c|c|c|c|c|c|c|c|c|}
\hline \multirow[b]{2}{*}{ No } & \multirow{2}{*}{$\begin{array}{l}\text { Jarak Tempat } \\
\text { PKL dengan } \\
\text { Aspal (cm) }\end{array}$} & \multicolumn{3}{|c|}{ Pasar Anduonohu } & \multicolumn{3}{|c|}{ Pasar Mandonga } & \multicolumn{3}{|c|}{ Tempat Pelelangan } & \multicolumn{2}{|c|}{ Total } \\
\hline & & Orang & $\begin{array}{c}\text { Lokasi } \\
(\%)\end{array}$ & $\begin{array}{l}\text { Total } \\
(\%)\end{array}$ & Orang & $\begin{array}{c}\text { Lokasi } \\
\text { (\%) }\end{array}$ & $\begin{array}{c}\begin{array}{c}\text { Total } \\
(\%)\end{array} \\
\end{array}$ & Orang & $\begin{array}{c}\text { Lokasi } \\
\text { (\%) }\end{array}$ & $\begin{array}{c}\text { Total } \\
\text { (\%) }\end{array}$ & Orang & $\%$ \\
\hline 1. & Diatas Aspal & 14 & 47 & 35 & 13 & 93 & 33 & 13 & 48 & 52 & 40 & 56 \\
\hline 2. & $1-25$ & 16 & 53 & 67 & 1 & 7 & 4 & 7 & 26 & 28 & 24 & 34 \\
\hline 3. & $26-50$ & 0 & 0 & 0 & 0 & 0 & 0 & 7 & 26 & 100 & 7 & 10 \\
\hline & Jumlah & 30 & 100 & & 14 & 100 & & 27 & 100 & & 71 & 100 \\
\hline
\end{tabular}

Sumber: Hasil Pengolahan Data

\section{- Biaya Lokasi}

Pedagang kaki lima menempati lokasi melalui preman yang berada disekitar pasar tanpa ada persetujuan dan dari PD pasar. Oleh karena itu pungutan tersebut dapat dinyatakan illegal dan harus ditindaki agar tidak menimbulkan peningkatan jumlah PKL di bahu jalan dan trotoar. Besaran tagihan yang diberikan dapat dilihat pada Tabel 17 paling tinggi di tempat pelelangan sebanyak Rp175.000 per bulan. Tagihan terendah pada Pasar Mandonga Anduonohu yang dibayar oleh 14 orang atau 82 persen PKL dan pada Pasar Anduonohu sebanyak 3 orang atau 18 persen. Tagihan pada 3 orang PKL tersebut berbeda dengan PKL pada lokasi yang sama sebesar Rp150.000 di Pasar Anduonohu karena PKL tersebut menjual menggunakan mobil open. Tabel 18 menunjukan tagihan harian sebesar
Rp5.000 per hari pada 3 orang PKL di Pasar Anduonohu merupakan tagihan tertinggi dibandingkan PKL lainnya di pasar ini hanya Rp2.000 per hari. Hal ini dikarenakan PKL yang membayar Rp5.000 per hari karena membayar tagihan bulanan Rp100.000. Pedagang kaki lima membayar tagihan bulanan dan harian kepada preman tanpa bukti pembayaran dapat dilihat dari hasil responden pada Tabel 19. Hal tersebut disampaikan pedagang di seluruh pasar. Kondisi ini sangat memprihatinkan sehingga PKL dalam posisi yang tersudutkan karena tidak dapat menjual di dalam pasar dengan alasan penuh dan tagihan lebih tinggi sedangkan menjual dibahu jalan dan trotoar yang merupakan pelanggaran namun tagihan bulanan dan harian tetap dibayar.

Tabel 17. Besaran Tagihan Bulanan Pedagang Kaki Lima oleh Preman, 2020

\begin{tabular}{|c|c|c|c|c|c|c|c|c|c|c|c|c|}
\hline \multirow[b]{2}{*}{ No } & \multirow{2}{*}{$\begin{array}{l}\text { Tagihan } \\
\text { Bulanan (Rp) }\end{array}$} & \multicolumn{3}{|c|}{ Pasar Anduonohu } & \multicolumn{3}{|c|}{ Pasar Mandonga } & \multicolumn{3}{|c|}{ Tempat Pelelangan } & \multicolumn{2}{|c|}{ Total } \\
\hline & & Orang & $\begin{array}{l}\text { Lokasi } \\
(\%)\end{array}$ & $\begin{array}{l}\text { Total } \\
\text { (\%) }\end{array}$ & Orang & $\begin{array}{c}\text { Lokasi } \\
\text { (\%) }\end{array}$ & $\begin{array}{l}\text { Total } \\
\text { (\%) }\end{array}$ & ang & $\begin{array}{l}\text { Lokasi } \\
\text { (\%) }\end{array}$ & $\begin{array}{c}\text { Total } \\
(\%)\end{array}$ & Drang & $\%$ \\
\hline 1 & 100.000 & 3 & 10 & 18 & 14 & 100 & 82 & 0 & 0 & 0 & 17 & 24 \\
\hline 2 & 150. & 27 & 90 & 100 & 0 & 0 & 0 & 0 & 0 & 0 & 27 & 38 \\
\hline 3 & 175.000 & 0 & 0 & 0 & 0 & 0 & 0 & 27 & 100 & 100 & 27 & 38 \\
\hline & Jumlah & 30 & 100 & & 14 & 100 & & 27 & 100 & & 71 & 100 \\
\hline
\end{tabular}

Sumber: Hasil Pengolahan Data

Tabel 18. Besaran Tagihan Harian Pedagang Kaki Lima oleh Preman, 2020

\begin{tabular}{cccccccccccccc}
\hline & Besaran & \multicolumn{3}{c}{ Pasar Anduonohu } & \multicolumn{3}{c}{ Pasar Mandonga } & \multicolumn{3}{c}{ Pelelangan } & \multicolumn{2}{c}{ Total } \\
\cline { 3 - 13 } No & $\begin{array}{c}\text { Tagihan } \\
\text { Harian } \\
(\mathrm{Rp})\end{array}$ & Orang & $\begin{array}{c}\text { Lokasi } \\
(\%)\end{array}$ & $\begin{array}{c}\text { Total } \\
(\%)\end{array}$ & Orang & $\begin{array}{c}\text { Lokasi } \\
(\%)\end{array}$ & $\begin{array}{c}\text { Total } \\
(\%)\end{array}$ & Orang & $\begin{array}{c}\text { Lokasi } \\
(\%)\end{array}$ & $\begin{array}{c}\text { Total } \\
(\%)\end{array}$ & Orang & $\%$ \\
\hline 1. & 2.000 & 27 & 90 & 50 & 0 & 0 & 0 & 27 & 100 & 108 & 54 & 76 \\
2. & 3.000 & 0 & 0 & 0 & 14 & 100 & 100 & 0 & 0 & 0 & 14 & 20 \\
3. & 5.000 & 3 & 10 & 100 & 0 & 0 & 0 & 0 & 0 & 0 & 3 & 4 \\
\hline & Jumlah & 30 & 100 & & 14 & 100 & & 27 & 100 & & 71 & 100 \\
\hline
\end{tabular}

Sumber: Hasil Pengolahan Data 
Tabel 19. Bukti Pembayaran Tagihan Bulanan dan Harian Pedagang Kaki Lima, 2020

\begin{tabular}{cccccccc}
\hline \multirow{2}{*}{$\begin{array}{c}\text { Menerima Bukti } \\
\text { Pembayaran }\end{array}$} & \multicolumn{2}{c}{$\begin{array}{c}\text { Pasar } \\
\text { Anduonohu }\end{array}$} & \multicolumn{2}{c}{ Pasar Mandonga } & \multicolumn{2}{c}{ Pelelangan } & Total \\
\cline { 2 - 8 } & Orang & $\begin{array}{c}\text { Total } \\
(\%)\end{array}$ & Orang & $\begin{array}{c}\text { Total } \\
(\%)\end{array}$ & Orang & Total (\%) & Orang \\
\hline Tidak & 30 & 42 & 14 & 20 & 27 & 38 & 71 \\
\hline
\end{tabular}

Sumber: Hasil Pengolahan Data

PKL biasanya datang tanpa izin tetapi mereka tak sepenuhnya dipesalahkan. Retribusi yang konon sudah dibayarkan kepada pihak tertentu menjadikan kehadirannya legal tetapi mereka tetap saja digusur. Agaknya Pemerintah Daerah perlu bersikap lebih bijaksana dalam menghadapi persoalan ini. Pembongkaran kios-kios mereka tidak memberikan solusi yang baik, namun penataan yang teratur terhadap keberadaan mereka sepertinya akan menjadi alternatif yang lebih santun (Mulyadi, 2010). Pola kelembagaan yang ada pada Pasar di Wilayah Kota Kendari yakni adanya keterikatan antara PKL dengan preman yang memungut biaya sebagai balas jasa PKL memperoleh tempat di bahu jalan atau trotoar.

\section{KESIMPULAN}

Berdasarkan uraian hasil dan pembahasan pada bab sebelumnya, maka dapat disimpulkan Karakteristik pedagang kaki lima (PKL): pekerjaan utama (87\%), jenis sayuran menjadi barang dagangan (14\%), lama berdagang $<5$ tahun (69\%), dan luas tempat 2-4 $\mathrm{m}^{2}$ (80\%). Faktor-faktor keberadaan pedagang kaki lima (PKL) menempati bahu jalan dan trotoar disekitar pasar di Kota Kendari adalah lemahnya penegakan aturan, sistem transaksional, tidak ada tempat di dalam pasar, dan biaya lokasi.

Ucapan Terima Kasih: Ucapan terimakasih di sampaikan kepada semua pihak yang telah berperan membantu dalam proses penelitian tata kelola kelembagaan pedagang kaki lima sekitar pasar di Kota Kendari sehingga dapat dituangkan dalam bentuk tulisan dan dapat di jadikan informasi bagi pembaca

\section{DAFTAR PUSTAKA}

Ardi. 2005. Praktik Premanisme di Lingkungan Pasar, Studi Etnografi Kalangan Pedagang Kaki Lima di Pasar Setongulon Surabaya. Fakultas Psikologi. Universitas Airlangga, Surabaya.

Creswell, J.W. 2012. Research Design. Pendekatan Kualitatif, Kuantitatif, dan Mixed. (KeTiga). Pustaka Pelajar. Yogyakarta

Ridwan dan Egkos A.K, 2011. Cara Menggunakan Dan Memaknai Analisis Jalur (Path Analysis) (Ketiga) Bandung: ALFABETA

Fitri, Dwi Agus Maulidiyah. 2016. Kriteria Lokasi Berdagang Pedagang Kaki Lima Berdasarkan Preferensi Pedagang Kaki Lima Di Kawasan Pasar Baru Gresik. Perencanaan Wilayah Kota Fakultas Teknik Sipil dan Perencanaan Institut Teknologi Sepuluh Nopember Surabaya

Handoyo, E., (2013). Kontribusi modal sosial dalam meningkatkan kesejahteraan pedagang kaki lima pasca relokasi. Jurnal komunitas, 5(2), 252-266

Kotler, P. 2002. Manajemen Pemasaran di Indonesia. (kedua). Salemba Empat Press. Jakarta.

Mulyadi, L. 2010. Studi Pengelolaan Pedaang Kaki Lima (PKL) di Kota Malang. Jurnal Sectra, 15 (8) 27-39

Sugiyono. 2010. Metode Penelitian Pendidikan Pendekatan Kuantitatif, Kualitatif, Dan $R$ \& D. ALFABETA. Bandung.

Yustika, A.E. (2006). Perekonomian Indonesia. BPFE-UNIBRAW. Malang 